\title{
Work careers in adults separated temporarily from their parents in childhood during World War II
}

Salonen, Minna K.

2019-03

Salonen , M K , von Bonsdorff , M B , Kautiainen , H , von Bonsdorff , M E , Kajantie , E , Wasenius , N S , Pesonen , A , Raikkonen , K \& Eriksson , J G 2019 , ' Work careers in adults separated temporarily from their parents in childhood during World War II ', Journal of Psychosomatic Research , vol. 118 , pp. 63-68 . https://doi.org/10.1016/j.jpsychores.2019.01.014

http://hdl.handle.net/10138/313331

https://doi.org/10.1016/j.jpsychores.2019.01.014

unspecified

publishedVersion

Downloaded from Helda, University of Helsinki institutional repository.

This is an electronic reprint of the original article.

This reprint may differ from the original in pagination and typographic detail.

Please cite the original version. 


\title{
Work careers in adults separated temporarily from their parents in childhood during World War II
}

\author{
Minna K. Salonen ${ }^{\mathrm{a}, \mathrm{b}, *}$, Mikaela B. von Bonsdorff ${ }^{\mathrm{a}, \mathrm{c}}$, Hannu Kautiainen ${ }^{\mathrm{a}, \mathrm{g}}$, \\ Monika E. von Bonsdorff ${ }^{c}$, Eero Kajantie ${ }^{\mathrm{b}, \mathrm{d}, \mathrm{e}}$, Niko S. Wasenius ${ }^{\mathrm{a}}$, Anukatriina Pesonen ${ }^{\mathrm{f}}$, \\ Katri Räikkönen ${ }^{\mathrm{f}}$, Johan G. Eriksson ${ }^{\mathrm{a}, \mathrm{b}, \mathrm{g}, \mathrm{h}, \mathrm{i}}$ \\ ${ }^{a}$ Folkhälsan Research Center, Helsinki, Finland \\ ${ }^{\mathrm{b}}$ National Institute for Health and Welfare, Department of Public Health Solutions, Chronic Disease Prevention Unit, Helsinki, Finland \\ ${ }^{\mathrm{c}}$ Gerontology Research Center, Faculty of Sport and Health Sciences, University of Jyväskylä, Jyväskylä, Finland \\ ${ }^{\mathrm{d}}$ Hospital of Children and Adolescents, Helsinki University Central Hospital, University of Helsinki, Helsinki, Finland \\ ${ }^{e}$ PEDEGO Research Unit, MRC Oulu, Oulu University Hospital, University of Oulu, Oulu, Finland \\ ${ }^{\mathrm{f}}$ University of Helsinki, Department of Psychology and Logopedics, Helsinki, Finland \\ ${ }^{\mathrm{g}}$ University of Helsinki, Helsinki University Hospital, Department of General Practice and Primary Health Care, Helsinki, Finland \\ ${ }^{\mathrm{h}}$ Singapore Institute for Clinical Sciences (SICS), Agency for Science and Technology (A*STAR), Singapore \\ ${ }^{i}$ Obstretics \& Gynecology, Yong Loo Lin School of Medicine, National University of Singapore, National University Health System, Singapore
}

\section{A R T I C L E I N F O}

\section{Keywords:}

Aging

Chronic disease

Labor force

Life cycle

Life stress

Separation

\begin{abstract}
A B S T R A C T
Introduction: Traumatic experiences, such as separation from parents in childhood causing early life stress (ELS) may increase the risk of adverse long-term health outcomes and biological age-related changes. This may have an impact on work career. Our aim was to examine long term consequences of ELS due to temporary separation from parents during World War II (WWII) in relation to work career.

Material and methods: The Helsinki Birth Cohort Study comprises 13,345 individuals born in Helsinki, Finland, between the years 1934-1944. From the original cohort, 1781 individuals were identified as being separated temporarily from their parents due to World War II. Information on date and type of pension was provided by the Finnish Centre for Pensions and the Social Insurance Institution of Finland. The cohort members either transitioned into old age pension at the statutory retirement age or retired earlier and transitioned into disability, unemployment, part-time pension or died before retirement.

Results: Those who were separated were more likely to have transitioned into disability pension (RRR: 1.26: 95\% CI: 1.06-1.48), especially due to diseases of the musculoskeletal system (OR: 1.57 ; 95\% CI: $1.20-2.07$ ), or into unemployment pension (RRR: 1.25; 95\% CI: 1.02-1.53) compared with those not separated from their parents. Longer duration of separation was associated with early exit from the workforce compared with non-separation. Conclusions: Exposure to ELS may have an impact upon lifetime work career. Early interventions preventing exposure to ELS or mitigating its negative effects may prolong future work careers along with healthier aging across the life-span.
\end{abstract}

\section{Introduction}

Severe, traumatic conditions and experiences early in life such as war, temporary separation from parents due to war, childhood abuse, neglect or severe illness in the family are important sources of early life stress (ELS) and may lead to an increased risk of adverse health outcomes across the life span [1]. For example, separation from parents due to World War II (WWII) is a known risk factor for mental health disorders in later life [2-5] that could persist across generations [6] and may induce physiological and biological changes and pathologies (such as poor physical and psychosocial functioning, frailty, type 2 diabetes and cardiovascular disease) $[7,8]$.

The results of a recent extensive study by Hughes et al. that examined the mentioned associations between ELS and unfavorable health outcomes show that those having multiple childhood adversities were at higher risk for a variety of poor health outcomes and health related behaviors [9]. Furthermore, other recently published studies showed that childhood adversities were associated with permanent

\footnotetext{
* Corresponding author at: National Institute for Health and Welfare, Chronic Disease Prevention Unit, P.O.X 30, FI-00271 Helsinki, Finland.

E-mail address: minna.salonen@thl.fi (M.K. Salonen).
} 
sickness, part-time employment and earlier retirement age at 55 years [10] and that childhood psychosocial adversity and low adult socioeconomic status were additive risk factors for work disability [11].

Many governments have introduced pension reforms in order to deal with continuously growing public expenditures due to the greying of the population in OECD countries. For example, in 1950's there were more than seven working-aged persons for each retired person but by the year 2050, the ratio will be two for one [12]. To control for increasing costs, early exit from labor market has been reduced through e.g. changes to retirement legislation and by rising the statutory retirement age [13].

Understanding the way in which work career in later life may be influenced by childhood ELS is of importance in terms of the designing and implementing proactive, early intervention aiming to prolong future work careers along with healthier aging across the life course. To the best of our knowledge, no studies have investigated the association between ELS due to parental separation during wartime evacuations and subsequent work career exits. Thus, by using data across the life course from the Helsinki Birth Cohort Study (HBCS), we aimed to study whether age of statutory retirement and early exit from the workforce due to disability pension, unemployment pension, part time pension or death before retirement differed between those who were exposed to ELS and those who were not. In the HBCS, data on war time separation were used to define ELS. During WWII a proportion of the HBCS cohort had been temporarily separated from their families due to evacuations of children to temporary foster families in Sweden or Denmark. We also examined whether those who transitioned into disability pension due to mental disorders, the diseases of musculoskeletal system, cardiovascular diseases, and diseases of nervous system or "all other reasons" differed according to wartime separation status.

\section{Materials and methods}

HBCS comprises 13,345 men and women who were born in Helsinki, Finland at Helsinki University Central Hospital or City Maternity Hospital between the years 1934 and 1944 [14,15]. In the year 1971 all residents of Finland were assigned an individual identification number which was used to link data from several national registers up to the end of year 2013.

Using the Register of the Finnish National Archives, managed by the Ministry of Social Affairs and Health between the years 1939 and 1946, $1781(13.3 \%)$ individuals from the original cohort were identified as having been separated temporarily from their biological parents and sent abroad as children due to WWII [2,16]. Although the register is of high quality and includes most of the evacuations, some children were also evacuated privately through personal contacts $[2,16]$.

Of the original cohort, we excluded those with missing data on retirement $(n=112)$, those who had migrated before retirement $(n=507)$ and those who had reported being evacuated, but whose information could not be found in the register of the Finnish National Archives $(n=189)[2,16]$. Hence, the final study population included 12,537 men and women of whom 1645 had been evacuated abroad in childhood. The study complies with the guidelines of the Declaration of Helsinki and was approved by the Ethics Committee of Epidemiology and Public Health of the Hospital District of Helsinki and Uusimaa and the National Public Health Institute.

\subsection{Early exit from the workforce}

While the average retirement age in OECD countries in 2014 was 64.6 years for men and 63.1 years for women [13], in 2011 in Finland, the average age of statutory retirement was 60.5 years and of those who transitioned into disability retirement, a third had retired by the age of 52 years [17]. In Finland, the National Pension Act was carried out in 1937 in order to secure pension in case of old age or disability. All Finnish residents who had lived in Finland for at least 3 years after they turned 16 years are covered by the pension system. Until 2005, the statutory retirement age was 63-65, and from 2005 to 2016 63-69 years but certain professions, such as firemen, pilots and army officers, had younger retirement ages. Approximately $5 \%$ of the cohort continued working after the age of 65 years (e.g. entrepreneurs in the private sector), and there are no retirement data available for these cohort members [18]. Among those who transitioned into old-age pensions, 90\% retired at the age of 58-65 years [19].

Information on date and type of pension was provided by the Finnish Centre for Pensions and the Finnish Social Insurance Institution. Information on death was obtained from the Finnish Population Register Centre. In the present study early exit from the workforce meant that the person transitioned into retirement before statutory pension age due to disability pension, unemployment or part-time pension or they died before retiring and thus did not reach a full work career. Disability pension is granted when a person is unable to continue working due to a medically confirmed illness whilst a part-time pensioner is partly working and partly retired based on their own whish (a person could retire on a part-time pension at the age of 61, providing their working life before retirement was long enough), or impaired working capacity due to medical condition. Criteria to qualify for pensions are described in more detail elsewhere [17-20].

Medically confirmed main causes of disability pensions were coded as according to the International Classification of Diseases (ICD) 9th and 10th versions into the following groups: mental disorders (ICD 9 codes 290-319 and ICD 10 codes F00-F99), diseases of musculoskeletal system (710-739 and M00-M99), cardiovascular diseases (400-459 and I00-I99), diseases of the nervous system (320-359 and G00-G99) and all other diagnoses.

\subsection{Socioeconomic background}

Childhood socioeconomic status was based on father's highest occupation at birth, child welfare and school healthcare records and was coded as high official, low official and manual workers based on the original social classification system by Statistics Finland [21]. Information on adult socioeconomic status was available from a register kept by the Statistics Finland, recorded at 5-year intervals between the years 1970-2000. We used the highest achieved occupation and it was coded as high official, low official, self-employed and manual workers. In a similar way, educational attainment was available at 5-year intervals between the years 1970-2000 and the highest achieved educational level is used in the analysis.

\subsection{Statistical methods}

Characteristics of the study population between the separated and non-separated were compared using $t$-test for continuous variables and $\chi^{2}$-square test for categorical variables. In order to reduce the effects of confounding and mitigate against the potential selection bias [22] multinomial logistic regression analyses using inverse probability of treatment weighting method (IPTW) were used to calculate the relative risk ratios (RRR) and 95\% confidence intervals (CI) for the types of early exit from the workforce according to separation status, old age pension being the reference category. Models were adjusted for the following covariates: sex (when both sexes were combined), birth order, maternal age (both based on the birth records of maternal hospitals), childhood socioeconomic status and year of birth. Birth order was categorised as follows: firstborn, the second, the third or later. Further adjustments for adulthood socioeconomic status, or alternatively educational attainment, did not alter the results. In a similar way, multinomial logistic regression using IPTW-method (based on the covariates mentioned above) was used to calculate RRRs for the main causes of disability pension. Binary logistic regression was used to calculate odds ratios (OR) for disability pension (all types combined) as well as for early exit from the workforce according to age at the first 
Table 1

Characteristics of the study population (mean and standard deviation unless stated otherwise) according to separation status in men and women.

\begin{tabular}{|c|c|c|c|c|c|c|c|}
\hline & \multicolumn{4}{|c|}{ Men } & \multicolumn{3}{|l|}{ Women } \\
\hline & \multirow{2}{*}{$\begin{array}{l}\mathrm{N} \\
12,537\end{array}$} & \multicolumn{3}{|c|}{ Separation status } & \multicolumn{3}{|c|}{ Separation satus } \\
\hline & & Yes, $\mathrm{n}=903$ & No, $n=5756$ & p-Value & Yes, $\mathrm{n}=742$ & No, $n=5136$ & p-Value \\
\hline Maternal age (years) & 12,530 & $27.9(5.6)$ & $28.4(5.4)$ & $<0.01$ & $27.9(5.4)$ & $28.6(5.5)$ & 0.001 \\
\hline Birth order $(\%)$ & 12,532 & & & $<0.001$ & & & $<0.001$ \\
\hline 1 st & & 42.7 & 50.1 & & 41.6 & 48.8 & \\
\hline 2nd & & 26.7 & 28.1 & & 28.6 & 29.3 & \\
\hline$\geq 3$ rd & & 30.6 & 21.1 & & 29.8 & 21.9 & \\
\hline Whether born at the time of WWII & & & & $<0.001$ & & & $<0.001$ \\
\hline No, born before the 30th of November 1939 (\%) & 3755 & 28.9 & 72.9 & & 24.1 & 75.9 & \\
\hline Yes, born after the 30th of November $1939(\%)$ & 8782 & 7.9 & 92.1 & & 7.6 & 92.4 & \\
\hline Age at separation (years) & 1491 & $4.6(2.4)$ & - & - & $4.8(2.4)$ & - & 0.19 \\
\hline Duration of separation (years) & 1457 & $1.8(1.1)$ & - & - & $1.7(1.0)$ & - & 0.06 \\
\hline Childhood socioeconomic status (\%) & 12,211 & & & $<0.001$ & & & $<0.001$ \\
\hline High official & & 11.1 & 19.0 & & 10.9 & 17.3 & \\
\hline Low official & & 21.8 & 24.2 & & 22.7 & 24.9 & \\
\hline Manual worker & & 67.2 & 56.8 & & 66.4 & 57.8 & \\
\hline Educational attainment (\%) & 12,093 & & & $<0.001$ & & & $<0.001$ \\
\hline Basic or less & & 48.9 & 37.8 & & 52.9 & 45.0 & \\
\hline Upper secondary & & 25.1 & 26.0 & & 23.2 & 23.6 & \\
\hline Lower tertiary & & 18.5 & 22.9 & & 18.1 & 22.8 & \\
\hline Upper tertiary & & 7.6 & 13.3 & & 5.9 & 8.5 & \\
\hline Adult socioeconomic status (\%) & 11,866 & & & $<0.001$ & & & 0.07 \\
\hline High official & & 11.1 & 16.0 & & 8.0 & 9.5 & \\
\hline Low official & & 21.1 & 24.1 & & 53.2 & 51.7 & \\
\hline Self-employed & & 10.6 & 10.5 & & 7.2 & 9.7 & \\
\hline Manual worker & & 57.1 & 49.4 & & 31.6 & 29.1 & \\
\hline
\end{tabular}

Comparisons were carried out between those with and without separation status.

separation (if one had multiple periods of separations) and duration of separation; non-evacuated formed the reference category. The analyses according age at separation was firstly adjusted for sex and year of birth, and secondly, in addition to previous, also for birth order, maternal age as well as childhood socioeconomic status, and thirdly, also for duration of separation. The analyses for early exit from the workforce according to the duration of separation were adjusted in a similar way as the calculations according to age at separation, except the duration of separation was replaced with the age of separation. All the analysis included tests of interaction to assess whether the effects of separation varied by sex or childhood socioeconomic background. When interactions were not found, the results are presented as both sexes combined. Analyses were carried out with IBM SPSS (Statistical Package for Social Sciences) version 25 and for the treatment weighting models using STATA 14.1 (StataCorp LP, College Station, TX).

\section{Results}

Characteristics of the study population are presented in Table 1. Boys who were separated tended to be firstborns to younger mothers and were more likely born before WWII. They belonged to a lower socioeconomic class in childhood, were less educated and had lower socioeconomic status in adulthood than their non-separated peers. In a similar way the separated girls had younger mothers and tended to be more frequently firstborns, belonged to a lower childhood socio economic class and were less educated than the non-separated girls. However, there were no statistically significant differences according to separation status and adult socioeconomic status among the girls.

Fig. 1 shows the RRRs for both sexes combined and then separately for men and women for the four types of early exits from the workforce according to separation status with old age pension being the reference group. Relative to non-separated, those who were separated had higher risk ratios of transitioning into disability or unemployment pension. The analyses stratified according to gender revealed that in contrary to the women, these associations were statistically non-significant among men with an exception that having been separated decreased the RRRs of transitioning into part-time pension, the interaction between sex and separation status on transitioning into part-time pension being statistically significant $(\mathrm{p}=.004)$.

Findings of the associations between wartime separation status and the main causes of disability pension are shown in Table 2. Compared to those who were not separated as children, the separated ones had an increased risk of transitioning into disability pension due to diseases of musculoskeletal system (RRR 1.57 95\% CI 1.20-2.04).

Associations between age at and duration of wartime separation and transitioning into disability pension are shown in Table 3. Results from the analyses using in the first model show that a higher age at separation, from school-age ( $>7$ years), was associated with higher likelihood of transitioning into disability pension. However, after further adjustments, statistically significant associations were attenuated to non-significant, especially after adjustments for age at and duration of separation. When the associations between age at and duration of separation and early exit from the workforce were examined, longer duration of separation (over three years) was statistically significantly associated with early exit from the workforce and remained so after all adjustments (Table 4).

\section{Conclusions}

The main finding of this study is that those men and women who had been exposed to ELS due to evacuations during WWII were more likely to exit the labor market earlier due to disability or unemployment pension compared with those non-exposed to such ELS. The association was more evident among women than men. Men who had been separated from their parents during wartime were less likely to transit into part-time pension. These associations were independent of both, childhood and adulthood socioeconomic status, as well as educational attainment. Age of overall retirement was similar in the both ELS groups.

We also found that both men and women who were exposed to ELS had a higher relative risk of transitioning into disability pension due to diseases of the musculoskeletal system. Further, longer duration of 


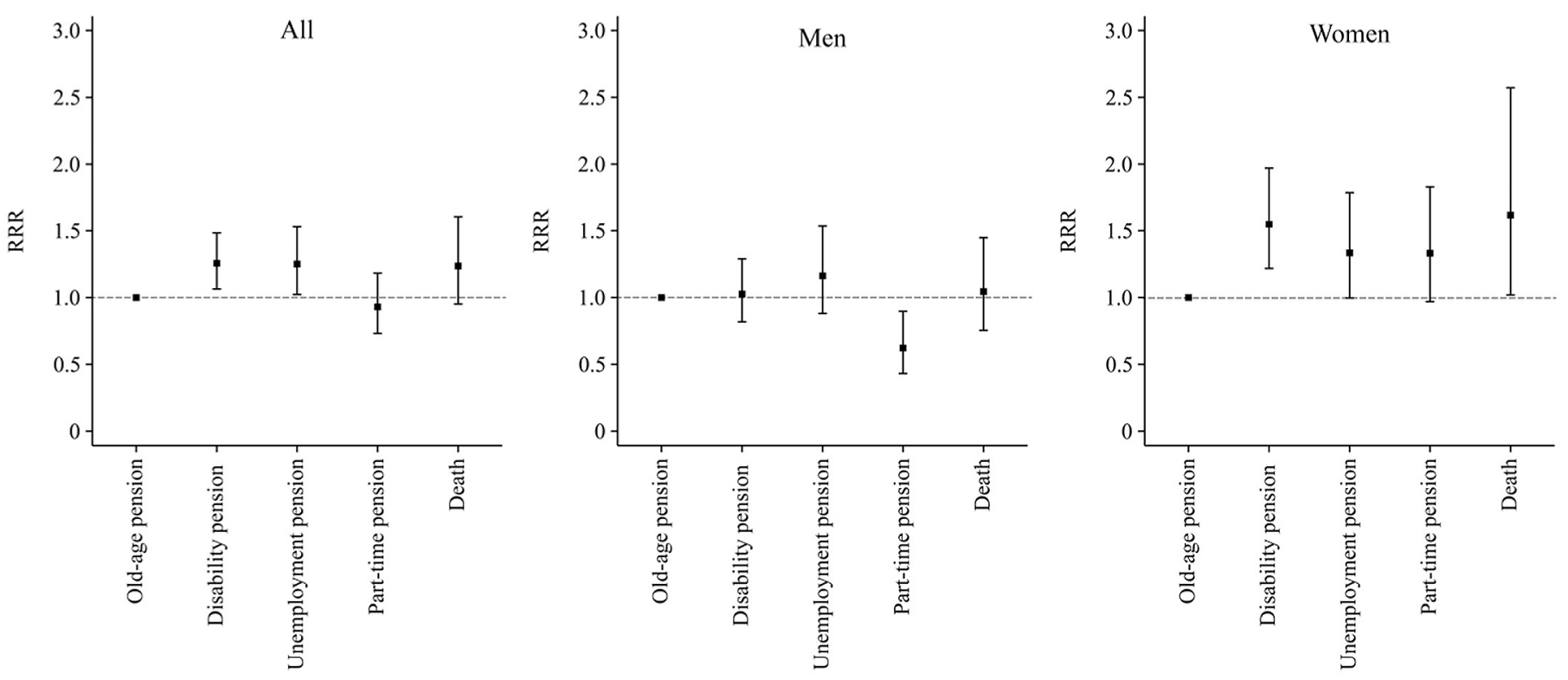

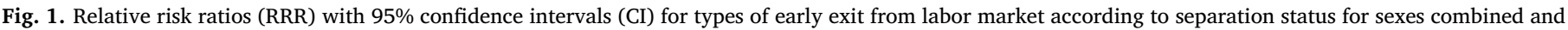
men and women separately. Calculations were made using a IPTW method based on parity, maternal age, childhood socioeconomic status and year of birth.

Table 2

Relative Risk Ratios (RRR) and 95\% confidence intervals for the main causes of disability pension among the men and women according to separation status old-age pension serving as a reference category.

\begin{tabular}{lllll}
\hline & $\mathrm{N} / \mathrm{n}^{\mathrm{a}}$ & $\mathrm{RRR}$ & $95 \% \mathrm{CI}$ & $\mathrm{p}$-Value \\
\hline Old-age pension & $4097 / 524$ & Ref. & Ref. & Ref. \\
Mental & $1145 / 191$ & 0.97 & $0.71-1.32$ & 0.844 \\
Musculoskeletal & $945 / 216$ & 1.57 & $1.20-2.04$ & $<0.001$ \\
Cardiovascular & $543 / 116$ & 1.04 & $0.73-1.5$ & 0.817 \\
Nervous & $293 / 51$ & 1.29 & $0.85-1.96$ & 0.230 \\
Other & $1100 / 215$ & 1.16 & $0.93-1.43$ & 0.182 \\
\hline
\end{tabular}

Inverse probability of treatment weighted multinomial logistic regression analysis based on sex, maternal age, birth order, childhood socioeconomic status and year of birth was applied.

${ }^{\text {a }} \mathrm{N} / \mathrm{n}$ indicates for the proportions of people belonging to old-age pension and type of disability pension group $(\mathrm{N}=$ non-separated and $\mathrm{n}=$ separated; one may have more than one diagnosis for the disability pension).

separation was associated with early exit from the workforce.

Separation from parents or the entire family as a child due to war may contain a variety of adversities such as a feeling of abandonment, neglect, even a death of a family member as well as cultural shock when one is being sent abroad unaccompanied. Childhood adversity may indirectly influence work career via conditions in adult life. For example, poorer mental and physical health, lower educational attainment, higher levels of risky health-related behaviors and reduced employment opportunities in early adulthood have previously been linked to childhood experience of adversity [23-25]. Findings from a recent study indicate that childhood psychosocial adversity and low adult socioeconomic status are additive risk factors for work disability, and the combination of these poses the greatest risk [11]. In line with our results, another recent study showed a significant association between childhood adversity and employment in later adulthood; experiences of adversity in childhood was associated with reduced labor force participation at late adulthood, particularly due to permanent sickness, even after taking into account aspects of adulthood such as qualifications and socio economic status [10].

Childhood and adolescence represent periods or critical windows during which exposure to stress may shape neurobiological and immune system development with changes persisting throughout the lifespan [25]. It has been shown that ELS has adverse influence on
Table 3

Odds ratios and 95\% confidence intervals (CI) for the disability pension according to the age at separation and duration of separation in men and women.

\begin{tabular}{|c|c|c|c|c|c|c|}
\hline & \multicolumn{2}{|c|}{ Model 1a } & \multicolumn{2}{|c|}{ Model 2a } & \multicolumn{2}{|c|}{ Model 3a } \\
\hline & OR & $95 \% \mathrm{CI}$ & OR & $95 \% \mathrm{CI}$ & OR & $95 \% \mathrm{CI}$ \\
\hline \multicolumn{7}{|l|}{ Disability pension } \\
\hline \multicolumn{7}{|l|}{$\begin{array}{l}\text { Age at separation } \\
\text { (years) }\end{array}$} \\
\hline Non separated & Ref. & & Ref. & & Ref. & Ref. \\
\hline Infancy $(<2)$ & 1.25 & $0.92-1.70$ & 1.18 & $0.86-1.61$ & 1.00 & $0.66-1.51$ \\
\hline Toddlerhood [2-4] & 1.13 & $0.92-1.38$ & 1.04 & $0.81-1.28$ & 0.89 & $0.64-1.24$ \\
\hline $\begin{array}{l}\text { Early childhood } \\
\text { [4-7] }\end{array}$ & 1.11 & $0.91-1.09$ & 1.04 & $0.85-1.28$ & 0.89 & $0.64-1.23$ \\
\hline \multirow[t]{3}{*}{ School age $(\geq 7)$} & 1.40 & $1.09-1.780$ & 1.32 & $1.02-1.71$ & 1.16 & $0.83-1.62$ \\
\hline & \multicolumn{2}{|c|}{ Model 1b } & \multicolumn{2}{|c|}{ Model 2b } & \multicolumn{2}{|c|}{ Model 3b } \\
\hline & OR & $95 \% \mathrm{CI}$ & OR & $95 \% \mathrm{CI}$ & OR & $95 \% \mathrm{CI}$ \\
\hline \multicolumn{7}{|l|}{ Disability pension } \\
\hline \multicolumn{7}{|l|}{$\begin{array}{l}\text { Duration of separated } \\
\text { (years) }\end{array}$} \\
\hline Non separated & Ref. & & Ref. & & Ref. & Ref. \\
\hline$\leq 1$ & 0.96 & $0.75-1.24$ & 0.92 & $0.71-1.19$ & 0.82 & $0.56-1.22$ \\
\hline $1-2$ & 1.26 & $1.07-1.49$ & 1.21 & $1.02-1.43$ & 1.08 & $0.76-1.53$ \\
\hline $2-3$ & 1.08 & $0.82-1.42$ & 1.01 & $0.76-1.35$ & 0.91 & $0.61-1.36$ \\
\hline$>3$ & 1.47 & $1.09-1.99$ & 1.23 & $0.90-1.68$ & 1.12 & $0.75-1.67$ \\
\hline
\end{tabular}

Model 1a is adjusted for sex and year of birth.

Model 2a is adjusted for sex, maternal age, birth order, childhood socioeconomic status and year of birth.

Model 3a is adjusted for sex, maternal age, birth order, childhood socioeconomic status, year of birth and duration of separation.

Model $1 \mathrm{~b}$ is adjusted for sex and year of birth.

Model $2 \mathrm{~b}$ is adjusted for sex, maternal age, birth order, childhood socioeconomic status and year of birth.

Model 3b is adjusted for sex, maternal age, birth order, childhood socioeconomic status, year of birth and age at separation.

cognitive function including decreased intellectual and academic performance, poorer language skills, and impairments in executive functioning such as planning and inhibitory control [26]. ELS has also been shown to be associated with long lasting impairments in affective functioning in terms of increased attention to negative stimuli, 
Table 4

Odds ratios and 95\% confidence intervals (CI) for early exit from the workforce according to the age at separation and duration of separation in men and women.

\begin{tabular}{|c|c|c|c|c|}
\hline & \multicolumn{2}{|c|}{ Model 1a } & \multicolumn{2}{|c|}{ Model 2a } \\
\hline & OR & $95 \% \mathrm{CI}$ & OR & $95 \% \mathrm{CI}$ \\
\hline \multicolumn{5}{|c|}{ Early exit from the workforce } \\
\hline \multicolumn{5}{|c|}{ Age at separation (years) } \\
\hline Non separated & ref. & & ref. & \\
\hline Infancy $(<2)$ & 1.29 & $0.96-1.75$ & 0.98 & $0.65-1.48$ \\
\hline Toddlerhood [2-4] & 1.24 & $1.02-1.51$ & 0.95 & $0.69-1.30$ \\
\hline Early childhood [4-7] & 1.23 & $1.00-1.51$ & 0.96 & $0.69-1.33$ \\
\hline \multirow[t]{3}{*}{ School age $(\geq 7)$} & 1.15 & $0.89-1.49$ & 0.85 & $0.60-1.21$ \\
\hline & \multicolumn{2}{|c|}{ Model 1b } & \multicolumn{2}{|c|}{ Model 2b } \\
\hline & OR & $95 \% \mathrm{CI}$ & OR & $95 \% \mathrm{CI}$ \\
\hline \\
\hline \multicolumn{5}{|c|}{ Duration of separated (years) } \\
\hline Non separated & ref. & & ref. & \\
\hline$\leq 1$ & 1.08 & $0.85-1.37$ & 1.13 & $0.77-1.66$ \\
\hline $1-2$ & 1.22 & $1.04-1.44$ & 1.26 & $0.89-1.78$ \\
\hline $2-3$ & 1.17 & $0.90-1.54$ & 1.17 & $0.79-1.74$ \\
\hline$>3$ & 1.79 & $1.27-2.53$ & 1.67 & $1.08-2.57$ \\
\hline
\end{tabular}

Model 1a is adjusted for sex and year of birth.

Model 2a is adjusted for sex, maternal age, birth order, childhood socioeconomic status, year of birth and duration of separation.

Model $1 \mathrm{~b}$ is adjusted for sex and year of birth.

Model $2 \mathrm{~b}$ is adjusted for sex, maternal age, birth order, childhood socioeconomic status, year of birth and age at separation.

difficulties in emotional regulation and increased risk of psychiatric illness, and impairments in reward-related decision-making as well as decreased motivation to pursue rewards [27,28]. It has been suggested, that cognitive and affective impairments may be salient as these may represent the mechanism by which childhood adversity may directly impact the capability of labor force participation among older adults. Results from a Finnish population based study provided some evidence of the direct pathway between childhood adversity and labor force participation among 40-54 non-retired men and women [29]. Furthermore, authors of another study conducted in Finland identified a cluster of young adults on permanent sickness leave due to mental illness, which were characterized by exposures to adversity during childhood. This study provides further evidence of a direct pathway between adversity and permanent sickness in terms of mental illness in adulthood [30]. Neuroendocrine systems, in terms of hypothalamicpituitary-adrenal (HPA) axis which is a regulator of stress response, have been shown to be affected by stress due to childhood abuse [31,32] and evacuations during WWII [16]. In addition, evidence suggests that the HPA axis is altered in aging Holocaust survivors [33].

ELS has been linked with hypertension, coronary heart disease, type 2 diabetes and depressive disorders with either contradictory or statistically non-significant sex differences, our present findings of this study reveals slight sex-specific differences while most of the findings were independent of sex. These findings are in line with our previous studies and those of others. In the present study we found that the separated men had a lower likelihood of ending up on part-time pension. It has been suggested that among those with childhood adversities a reduction in the involvement in part-time employment may be an indication of limited options in flexibility and a lower availability labor market and a lower availability of financial resources [10]. In Finland, the earnings of people moving into part-time pension have been higher than those of their peers with full-time employment status. When examined across all ages and before the take-up of part-time pension, net income (including wages and pension, excluding capital income and wealth) for those on part-time pension has been, on average, approximately $30 \%$ higher than that of their peers [34]. In addition, we have previously shown that the income trajectories across the working career in adulthood differed between the separated and non-separated in such a way that the group differences grew larger with years passing by, with those who were separated displaying a decrease in the taxable incomes [35].

Bowlby [36] suggested that early relationship between child and the parent, in other words, "attachment" plays an important or even crucial role in normal childhood development and long-term functioning. We found associations between duration of separation and early exit from the workforce, which both agree and disagree with previous findings from our cohort linking ELS caused by parental separation with several conditions in later life. In the present study those with the longest duration of separation had a higher likelihood of exiting the workforce early due to disability, unemployment, part-time pension or premature death compared to non-separated, which is in line with earlier studies indicating that longer duration of separation is potentially more harmful in terms of later health outcomes $[2,7,8]$. The previous study from our cohort which focuses on wartime separation and depressive symptoms found that the most affected group was those who had been evacuated for $>3$ years [2], whilst the other study based on our epidemiological cohort found no associations between the age at or duration of separation and severe mental disorders [4].

Why we found associations between ELS and diseases of musculoskeletal system rather than mental disorders? One explanation could be that mental disorders are often associated with musculoskeletal diseases and vice versa. Back pain and depression are strongly interlinked [37]. In Europe, up to one-third of subjects with chronic pain (primarily back pain) have also been diagnosed with depression [38]. In particular, pain intensity is known to be associated with anxiety, depression and poor sleep [39]. Which was the primary cause for the disability pension in this study - we unfortunately do not know for certain. In addition, until couple of decades ago, it was stigmatizing to be diagnosed with mental disorders in Finland, which may, at least partly, also explain our findings.

The strengths of this study include parent-child separation in a natural setting due to WWII enabling us to study ELS in relation to longterm health outcomes related to work career. We had register-based information on birth and socioeconomic background both in childhood and adult life from the long follow-up time covering the work career from early adulthood to retirement or premature death. We were able to use unique archive data on wartime evacuation including age at and duration of the separation [2]. Our data originate from the database of the nationwide social security system including information on income security and The Finnish Centre for Pensions, and data is objective and reliable [34,40].

There are limitations to be addressed. Not all evacuations were executed through the Finnish government and therefore some of the participants may have been misclassified as non-separated which, however, may rather dilute than strengthen the observed group differences. Further, we do not have information on the living conditions of the foster care during the wartime separation. Studying the long term effects of ELS on later life health outcomes is largely based on natural experiments designs indicating that there remains a possibility for confounders that cannot be taking into account, causing the influence of ELS to be subordinate to other, unknown adversities that caused ELS itself. We cannot be sure which of the children were selected to temporary foster care - they may have been the weakest, or the strongest and most healthy ones in the families. These aspects, among others, have been discussed previously [2,35]. Moreover, the cohort members were followed up from early adulthood when they were available for work until they exited the workforce or died. However, our register based data does not include precise information on whether the cohort members were actually working during the follow-up, and such data are not available in Finland - at least not for such a long follow-up time that is required in the present study. 
ELS in this very context might include one event or the sum of multiple adverse experiences affecting the healthy development of a child. Children exposed to war evacuations have at least two experiences of disruptions, the first being the separation from the initial family and then returning home years after the separation [35]. Secondly, some of the evacuees were being separated two or even three times during the war. These aspects may explain the somewhat contradictory findings on the role of age at and duration of separation on later health outcomes in different contexts.

Although our study represents unique conditions due to WWII in relation to separations, we believe that the findings apply to the children of today worldwide. In the contemporary world there is a massive amount of refugees, including children, who are being sent to foster care, and who are at severe risk of poverty as well as multiple kinds of adversities including maltreatment. In the year 2017 an estimated 16.2 million people were globally displaced including children or under aged (less than 18 years) who constitutes half $(52 \%)$ of the displaced population. Of these 4.4 million were newly displaced refugees and asylumseekers including 173,800 children who were unaccompanied or separated child refugees or asylum-seekers [41].

We conclude that ELS due to temporary separation from parents may have consequences on health in later life and thus lead to an increased risk for early exit from the workforce. Early interventions in order to prevent ELS or mitigate its negative effects may prolong future work careers along with healthier aging across the life-span.

\section{Disclosure statement}

The authors report no declarations of interest.

\section{Funding information}

H.B.C.S. was supported by Finnish Foundation for Cardiovascular Research, Juho Vainio Foundation, Signe and Ane Gyllenberg Foundation, Samfundet Folkhälsan, Finska Läkaresällskapet, Liv och Hälsa, EU H2020-PHC-2014-DynaHealth (grant no. 633595). The Academy of Finland (grant no. 257239 to M.B.v.B.); (grant no. 127437, 129306, 130326, 134791, 263924 and 274794 to E.K.); (grant no. 129369, 129907, 135072, 129255 and 126775 to J.G.E.).

\section{References}

[1] S.R. Dube, V.J. Felitti, M. Dong, W.H. Giles, R.F. Anda, The impact of adverse childhood experiences on health problems: evidence from four birth cohorts dating back to 1900, Prev Med (Baltim) 37 (2003) 268-277.

[2] A.-K. Pesonen, K. Räikkönen, K. Heinonen, E. Kajantie, T. Forsén, J.G. Eriksson, Depressive symptoms in adults separated from their parents as children: a natural experiment during World War II, Am. J. Epidemiol. 166 (2007) 1126-1133.

[3] J.S.M. Rusby, F. Tasker, Long-term effects of the British evacuation of children during World War 2 on their adult mental health, Aging Ment. Health 13 (2009) 391-404.

[4] K. Räikkönen, M. Lahti, K. Heinonen, A.-K. Pesonen, K. Wahlbeck, E. Kajantie, et al., Risk of severe mental disorders in adults separated temporarily from their parents in childhood: the Helsinki Birth Cohort Study, J. Psychiatr. Res. 45 (2011) 332-338.

[5] T. Santavirta, N. Santavirta, T.S. Betancourt, S.E. Gilman, Long term mental health outcomes of Finnish children evacuated to Swedish families during the second world war and their non-evacuated siblings: cohort study, BMJ 350 (2015) g7753.

[6] T. Santavirta, N. Santavirta, S.E. Gilman, Association of the world war II Finnish evacuation of children with psychiatric hospitalization in the next generation, JAMA Psychiatry 75 (2018) 21-27.

[7] H. Alastalo, K. Räikkönen, A.-K. Pesonen, C. Osmond, D.J. Barker, E. Kajantie, et al., Cardiovascular health of Finnish war evacuees 60 years later, Ann. Med. 41 (2009) $66-72$.

[8] H. Alastalo, M.B. Von Bonsdorff, K. Räikkönen, A.-K. Pesonen, C. Osmond, D.J. Barker, et al., Early life stress and physical and psychosocial functioning in late adulthood, PLoS One 8 (2013) e69011.

[9] K. Hughes, M.A. Bellis, K.A. Hardcastle, D. Sethi, A. Butchart, Christopher Mikton, et al., The effect of multiple adverse childhood experiences on health: a systematic review and meta-analysis, Lancet Public Health 2 (2017) e356-e366.

[10] A.E. Fahy, S.A. Stansfeld, M. Smuk, D. Lain, M. van der Horst, S. Vickerstaff, et al., Longitudinal associations of experiences of adversity and socioeconomic disadvantage during childhood with labor force participation and exit in later adulthood, Soc. Sci. Med. 83 (2017) 80-87.

[11] J.I. Halonen, M. Kivimäki, J. Vahtera, J. Pentti, M. Virtanen, J. Ervasti, et al.,
Childhood adversity, adult socioeconomic status and risk of work disability: a prospective cohort study, Occup. Environ. Med. 74 (2017) 659-666.

[12] OECD, Pensions at a Glance 2011: Retirement Income Systems in OECD and G20 Countries, OECD Publishing, Paris, 2011.

[13] OECD, Pensions at a Glance 2015: OECD and G20 Indicators, OECD Publishing, Paris, 2015.

[14] J.G. Eriksson, T. Forsén, J. Tuomilehto, P.D. Winter, C. Osmond, D.J. Barker, Catchup growth in childhood and death from coronary heart disease: longitudinal study, BMJ 318 (1999) 427-431.

[15] D.J. Barker, C. Osmond, T.J. Forsén, E. Kajantie, J.G. Eriksson, Trajectories of growth among children who have coronary events as adults, N. Engl. J. Med. 353 (2005) 1802-1809.

[16] A.-K. Pesonen, K. Räikkönen, K. Feldt, K. Heinonen, C. Osmond, D.I. Phillips, et al., Childhood separation experience predicts HPA axis hormonal responses in late adulthood: a natural experiment of World War II, Psychoneuroendocrinology 35 (2010) 758-767.

[17] Official Statistics of Finland, Pensioners and Insured in Finland 2011, Finnish Center for Pensioners, Helsinki, 2013.

[18] M.B. von Bondorff, T. Törmäkangas, M.K. Salonen, M.E. von Bonsdorff, C. Osmond, E. Kajantie, et al., Johan G. Early life origins of all-cause and cause specific disability pension: findings from the Helsinki Birth Cohort Study, PlosOne. 10 (2015) e0122134.

[19] M.B. von Bonsdorff, M.E. von Bonsdorff, M. Haanpää, M. Salonen, T.M. Mikkola, H. Kautiainen, et al., Work-loss years among people diagnosed with diabetes: a reappraisal from a life course perspective, Acta Diabetol. 55 (2018) 485-491.

[20] https://www.etk.fi/en/the-pension-system/pension-security/earnings-relatedpension-benefits/part-time-pension/.

[21] Central Statistical Office of Finland, Classification of Socioeconomic Groups: Handbooks, 17 Central Statistical Office of Finland, Helsinki, Finland, 1989.

[22] M.D. Cattaneo, Efficient semiparametric estimation of multi-valued treatment ef fects of under ignorability, J. Econ. 155 (2010) 138-154.

[23] R.F. Anda, F.J. Felitti, J.D. Bremner, J.D. Walker, C. Whitfield, B.D. Perry, et al., The enduring effects of abuse and related adverse experiences in childhood, Eur. Arch. Psychiatry Clin. Neurosci. 256 (2006) 174-186.

[24] C. Clark, T. Caldwell, C. Power, S.A. Stansfeld, Does the influence of childhood adversity on psychopathology persist across the lifecourse? A 45-year prospective epidemiologic study, Ann. Epidemiol. 20 (2010) 385-394.

[25] S.R. Dube, V.J. Felitti, M. Dong, D.P. Chapman, W.H. Giles, R.F. Anda, Childhood abuse, neglect, and household dysfunction and the risk of illicit drug use: the adverse childhood experiences study, Pediatrics 111 (2003) 564-572.

[26] M.H. Teicher, S.I. Andersen, A. Polcari, C.M. Anderson, C.P. Navalta, D.M. Kim, The neurobiological consequences of early stress and childhood maltreatment, Neurosci. Biobehav. Rev. 27 (2003) 33-44.

[27] P. Pechtel, D.A. Pizzagalli, Effects of early life stress on cognitive and affective function: an integrated review on human literature, Psychopharmacology 214 (2011) 55-70.

[28] E. Ford, C. Clark, S.A. Stansfeld, The influence of childhood adversity on social relations and mental health at mid-life, J. Affect. Disord. 133 (2011) 320-327.

[29] K. Harkonmäki, K. Korkeila, J. Vahtera, M. Kivimäki, S. Suominen, L. Sillanmäki, et al., Childhood adversities as a predictor of disability retirement, J. Epidemiol. Community Health 61 (2007) 479-484.

[30] M. Joensuu, P. Mattila-Holappa, K. Ahola, J. Ervasti, M. Kivimäki, Kivekäs et al Clustering of adversity in young adults on disability pension due to mental disorders: a latent class analysis, Soc. Psychiatry Psychiatr. Epidemiol. 51 (2016) $281-287$.

[31] L.L. Carpenter, A.R. Tyrka, N.S. Ross, L. Khoury, G.M. Anderson, L.H. Price, Effect of childhood emotional abuse and age on cortisol responsitivity in adulthood, Biol. Psychiatry 66 (2009) 69-75.

[32] M.R. Gunnar, K. Frenn, S.S. Wewerka, M.J. Van Ryzin, Moderate versus severe early life stress: associations with stress reactivity and regulation in 10-12-year-old children, Psychoneuroendocrinology 34 (2009) 62-75.

[33] R. Yehuda, J.A. Golier, P.D. Harvey, K. Stavitsky, S. Kaufman, R.A. Grossman, et al., Relationship between cortisol and age-related memory impairments in Holocaust survivors with PTSD, Psychoneuroendocrinology 30 (2005) 678-687.

[34] J. Salonen, M. Takala, Working career and income of part-time pensioners in Finland, Working Papers, Finnish Centre for Pensions, 2011, p. 2 http://www.etk. fi/en/julkaisu/working-career-and-income-of-part-time-pensioners-in-finland-2/.

[35] A.K. Pesonen, K. Räikkönen, E. Kajantie, K. Heinonen, C. Osmond, T. Forsén, et al., Inter-generational social mobility following early life stress, Ann. Med. 43 (2011) 320-328.

[36] J. Bowlby, The making and breaking of affectional bonds. I. Aetiology and psychopathology in the light of attachment theory. An expanded version of the Fiftieth Maudsley Lecture, delivered before the Royal College of Psychiatrists, 19 November 1976, Br. J. Psychiatry 130 (1977) 201-210, https://doi.org/10.1192/bjp.130.3. 201.

[37] J. Carstensen, D. Andersson, M. Andre', S. Engström, H. Magnusson, L.A. Borgquist, How does comorbidity influence healthcare costs? A population-based cross-sectional study of depression, back pain and osteoarthritis, BMJ Open 2 (2012) e000809, , https://doi.org/10.1136/bmjopen-2011-000809.

[38] H. Breivik, B. Collett, V. Ventafridda, R. Cohen, D. Gallacher, Survey of chronic pain in Europe: prevalence, impact on daily life, and treatment, Eur. J. Pain 10 (2006) 287-333.

[39] J. Kwak, H.K. Kim, T. Kim, S.H. Jang, K.H. Lee, M.J. Kim, et al., The Prevalence and Characteristics of Depression in Work-related Musculoskeletal Disease, Ann. Rehabil. Med. 36 (2012) 836-840.

[40] Official Statistics of Finland, Pensioners and Insured in Finland 2011, Finnish Centre for Pensioners, Helsinki, 2013.

[41] The UN Refugee Agency (UNCHR), Global Trends, Forced Displacement in 2017, http://www.unhcr.org/globaltrends2017/, (2017). 